Article

\title{
Incorporating Public Participation in Offshore Wind Farm Siting in Greece
}

\author{
Eva Loukogeorgaki ${ }^{1}$, Dimitra G. Vagiona ${ }^{2, *(1)}$ and Areti Lioliou ${ }^{1}$ \\ 1 Department of Civil Engineering, Aristotle University of Thessaloniki, 54124 Thessaloniki, Greece; \\ eloukog@civil.auth.gr (E.L.); aretilioliou92@gmail.com (A.L.) \\ 2 Department of Spatial Planning and Development, Aristotle University of Thessaloniki, \\ 54124 Thessaloniki, Greece \\ * Correspondence: dimvag@plandevel.auth.gr; Tel.: +30-2310-99-5954
}

Citation: Loukogeorgaki, E.; Vagiona, D.G.; Lioliou, A. Incorporating Public Participation in Offshore Wind Farm Siting in Greece. Wind 2022, 2, 1-16 https://doi.org/10.3390/ wind2010001

Academic Editor: Yingyi Liu

Received: 30 November 2021

Accepted: 24 December 2021

Published: 4 January 2022

Publisher's Note: MDPI stays neutral with regard to jurisdictional claims in published maps and institutional affiliations.

Copyright: (C) 2022 by the authors. Licensee MDPI, Basel, Switzerland. This article is an open access article distributed under the terms and conditions of the Creative Commons Attribution (CC BY) license (https:// creativecommons.org/licenses/by/ $4.0 /)$.

\begin{abstract}
The public acceptance of Offshore Wind Farms (OWFs) is an important issue that is expected to depend highly on their site location. Public involvement in decision-making processes is recommended as it may contribute to the mitigation of opposing, delaying and even blocking OWF projects, as well as increasing future public confidence and support. The aim of this study is to identify the most suitable sites for OWFs deployment in Greece based on citizens' preferences and judgments. The methodology consists of three phases: (i) identification of Eligible Marine Areas (EMAs) for OWF siting by deploying ten exclusion criteria, (ii) prioritization of six evaluation criteria and ranking of EMAs according to citizens' judgments through an Online Questionnaire Survey (OQS) and (iii) overall prioritization of EMAs. The Analytic Hierarchy Process (AHP), supported by Geographic Information Systems (GIS) and the OQS are used for the analysis. The results illustrate the priority ranking of thirteen EMAs for OWFs deployment in the Greek marine environment under five different scenarios. The most suitable sites are located in the South-West zone offshore of Rhodes in all the examined scenarios. Sustainable development is a challenging social process, and the different preferences of the society should be integrated in planning processes.
\end{abstract}

Keywords: public participation; offshore wind farms; site selection; exclusion criteria; evaluation criteria; GIS; AHP; Greece

\section{Introduction}

Renewable Energy Sources (RES) have gained the interest of both the scientific community and the investors during the last decades. RES is a domestic energy source for many countries, with perspectives of development both locally and nationally. One of the most widespread RES is wind energy. During the last decade, the point of interest in wind energy, mainly in Europe, has moved from onshore to offshore locations, taking advantage of the higher and steadier wind speeds met in the open sea [1]. In this way, it is possible to produce "environmentally friendly" energy in small countries, such as Greece, where, on the one hand, the appropriate and available land areas for wind farm siting are limited, due to many spatial constraints, and on the other hand, there is a plethora of marine areas that could be used for this purpose.

Wind farm siting requires the appropriate collection, analysis and accurate display of spatial data that are related to various sustainable siting criteria (environmental, economic, technical and social criteria). The above can be implemented effectively using Geographic Information Systems (GIS), which are information systems enabling the collection, organization, storage, manipulation, management, processing, analysis, modeling and visualization of large amounts of data linked to a matrix in the form of a spatial reference in a digital environment. ArcGis and GvSig are the most used software tools to help with localization [2]. In addition, wind farm siting is a complex and multidimensional decision-making 
process, which should consider multiple and even conflicting criteria and objectives. Multicriteria Decision Making (MCDM) methods, which are typical decision-making methods, can be a key tool for selecting the "optimal" wind farm location. The evaluation realized within an MCDM method enables the comparison of different elements according to their characteristic properties in order to select the best wind farm localization alternative [3]. The most frequent MCDM method used for assigning weights to decision criteria in wind energy siting research is the analytic hierarchy process (AHP) method [4]. In many cases, combinations of GIS and MCDM methods are conducted to achieve the desired results both in onshore (e.g., [5-9]), and offshore wind farm siting studies (e.g., [10,11]).

An extremely important issue in the decision-making process for the deployment of wind energy projects is public (citizens') involvement and participation. Considering that the development of wind farm projects depends on the location of wind turbines, its acceptance and possible impacts and benefits to local communities are often contested [12]. In order to plan for socially accepted projects, it is essential to incorporate residents perceptions during the planning stage. While engagement is not a panacea and does not provide a guarantee of gaining public support, engaging the public in a meaningful manner may be a critical component to address public opposition and mistrust of renewable energy projects [13].

Although social acceptance is listed in several scientific papers (e.g., [14-16]) that aim to find out the local community opinions about wind farm installation projects and factors that influence community acceptance [17], there are really handful studies that incorporate public opinion in wind farm siting. Spyridonidou and Vagiona [4] revealed, in a systematic review of site-selection processes in wind energy research, that thirteen onshore (e.g., [18-21]) and only four offshore wind farm siting studies (e.g., [22]) have incorporated participatory planning within their site-selection frameworks. However, there is a tendency from wind energy planners to primarily incorporate expert groups or stakeholders in participatory site-selection processes and, thus, there is a gap in public (citizens') participation. To the authors' knowledge, there are only a handful of onshore wind farm studies that engage the local residents, among which only Gorsevski et al. [23] reported the number of participants, which was equal to 30. In the Offshore Wind Farm (OWF) siting literature, only Mekonnen and Gorsevski [22] deployed a conceptual web-based participatory geographic information prototype, integrating GIS and decision-making tools and involving only stakeholders for solving complex planning problems and building consensus on a hypothetical case study of an OWF deployment within Lake Erie, Ohio. In recent years, an increase in citizens who are opposed to the deployment of wind energy projects has been noticed. This negative attitude towards renewable energy projects, together with the argument that citizens' participation in the planning process is critical for their acceptance, motivated the current research.

Along these lines and aiming at filling existing research gaps, the present paper focuses on the active involvement of the public (citizens) in the selection of the most feasible locations for installing OWFs, considering Greece as the study area. For this purpose, a methodological site-selection process of three successive phases is developed and applied, based on the combined use of GIS, AHP and an Online Questionnaire Survey (OQS) that gathers citizens' preferences towards OWF siting issues in a twofold way as further explained below. The developed methodology advances the direct inclusion of citizens' preferences and judgments within the site-selection process of OWFs, which presents the main novelty of the present work. Furthermore, overall prioritization of eligible marine areas (EMAs) is realized by introducing and deploying "social acceptance" as an evaluation criterion along with five more criteria representing techno-economic factors. Using the proposed appropriate participatory approach, the final decision about an OWF development is either shared with or even rests with the community. In the first phase of the developed site-selection process, EMAs for OWF siting are identified based on a set of exclusion criteria and the deployment of GIS. The second phase includes the OQS and aims at the prioritization of the six evaluation criteria as well as the ranking 
of the aforementioned EMAs, according to citizens' relevant judgments and preferences. Accordingly, the relative weights of the evaluation criteria with respect to the overall goal of the present site-section process, and of the EMAs with respect to the "social acceptance" evaluation criterion are quantified. These weights are, then, deployed as input in the third phase of the developed process, where EMAs are evaluated and ranked using AHP, and the most suitable and socially acceptable sites for OWF deployment in Greece are determined. Finally, a sensitivity analysis is performed for the first time to investigate the degree of uncertainty in the decision-making process, based on various scenarios formulated according to different target groups' judgments.

The remainder of this paper is organized as follows. Section 2 describes the study area as well as the methodological approach of the OWF siting developed and applied in the present paper, including both the exclusion and the evaluation criteria. In Section 3, the outcomes of the present study are presented and discussed, while the main conclusions of this research are revealed and discussed in Section 4.

\section{Materials and Methods}

\subsection{Study Area}

Greece is a country located in Southeast Europe, sharing land borders with Albania to the North-West, North Macedonia and Bulgaria to the North, and Turkey to the North-East, and it is surrounded by the Aegean Sea in the East, the Ionian Sea in the West and the Mediterranean Sea in the South. In addition, Greece shares maritime borders with Italy, Libya, Egypt, Cyprus, Albania and Turkey. The area of Greece is estimated at 131,957 km², while its population is approximately 10.7 million as of 2018. It has an extensive coastline $(13,676 \mathrm{~km}$ in length) and is characterized by its numerous islands, with estimates ranging from somewhere around 1200 [24] to 6000 [25], depending on the minimum size to take into account. The extensive marine area in Greece allows for continuous development of various activities, such as tourism, shipping, fishing, military activities, etc. [11]. The study area of this research is defined by the Greek coastline of the country along with the geographical boundaries of the Greek marine area and it is shown in Figure 1.

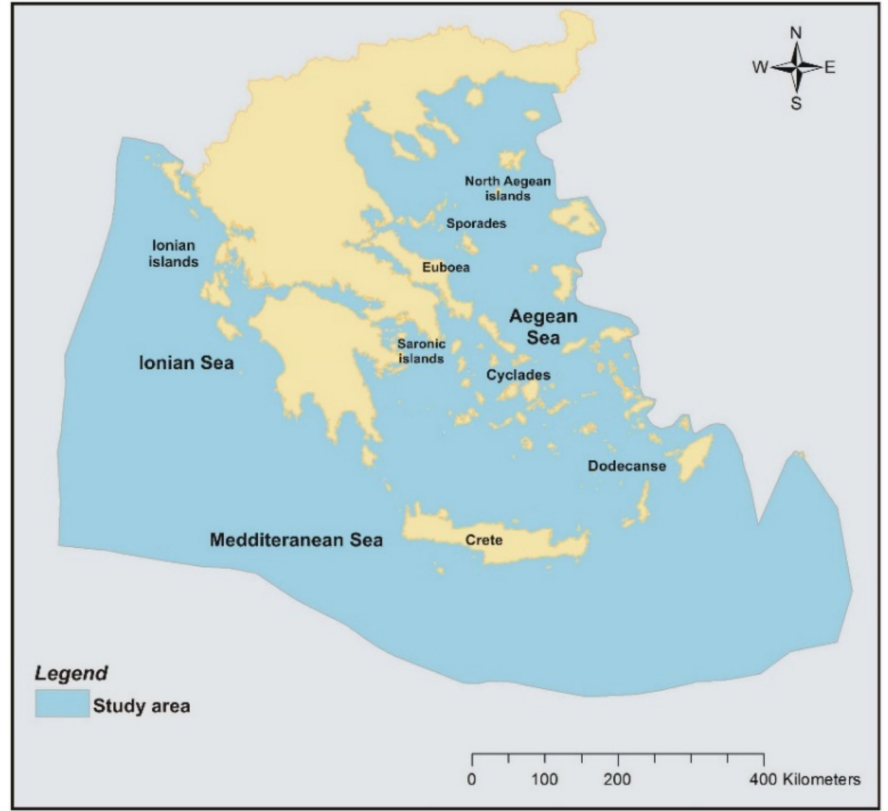

Figure 1. Study area of the present investigation.

\subsection{Methodological Process for OWF Site Selection}

In order to prioritize the most suitable and socially accepted marine areas for OWF siting in Greece, a methodological site-selection process, presented in Figure 2, was developed 
and applied. The process consists of three successive phases. In the first (exclusion) phase, we identify EMAs for OWF siting by deploying ten exclusion criteria related to utilization restrictions, economic, social and technical constraints. In the second (public participation) phase, prioritization of six evaluation criteria as well as ranking of EMAs, as obtained from the first phase of the site-selection process, are implemented according to citizens' relevant judgments and preferences. Finally, the third (evaluation) phase includes the evaluation and the overall prioritization ranking of EMAs. For this purpose, six evaluation criteria are deployed. Five of them represent techno-economic factors, while the sixth one corresponds to the social acceptance (SA), describing the degree of suitability of an EMA according to the citizens' preferences. Three tools and techniques are used for the analysis, namely, GIS (in all three phases), OQS (second and third phases) and AHP (third phase).

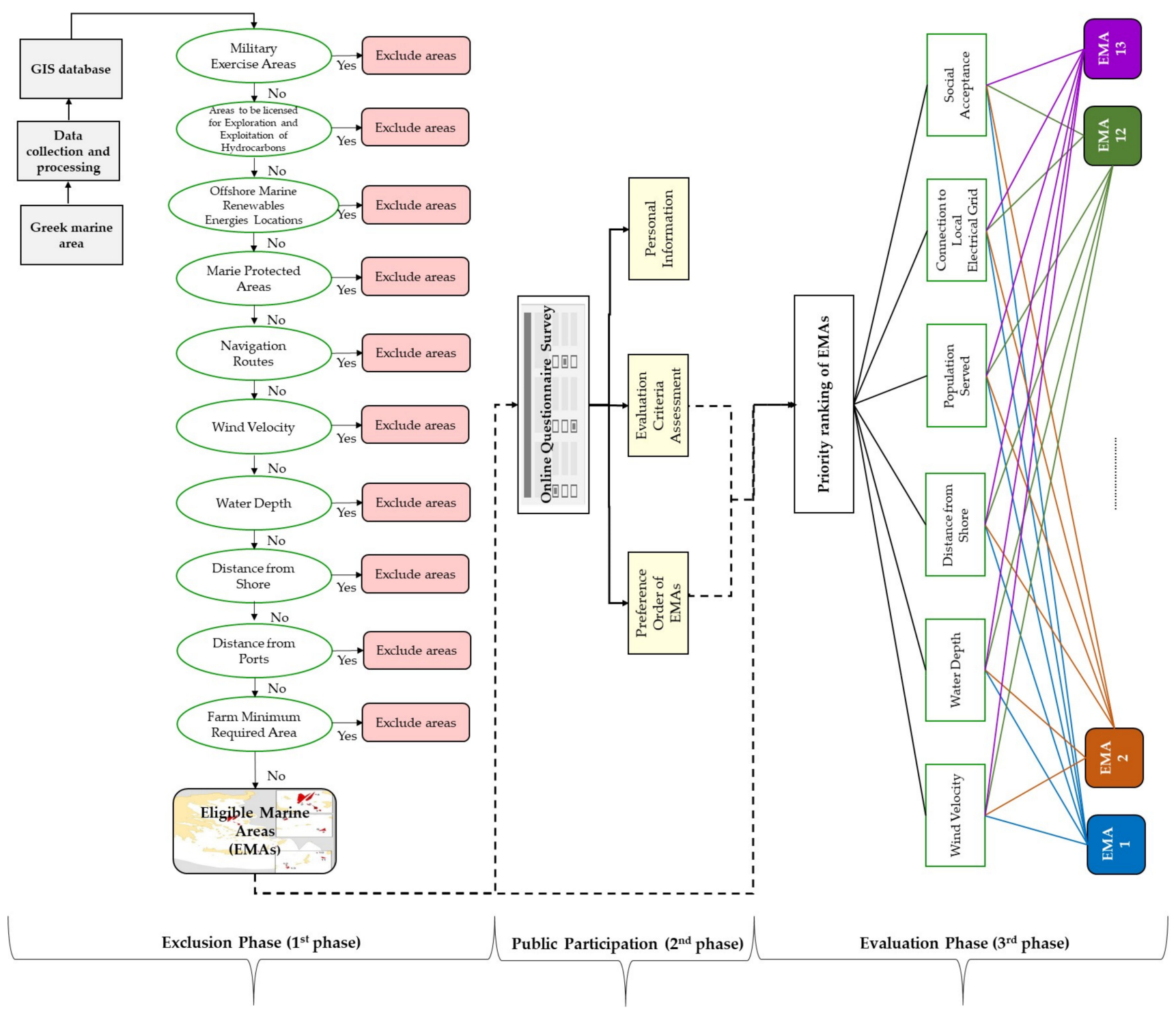

Figure 2. Methodological process for site selection of OWFs in the Greek marine environment.

\subsubsection{Exclusion Phase ( $1^{\text {st }}$ Phase)}

In the $1^{\text {st }}$ phase of the analysis, unsuitable areas for OWF siting were identified through the development of a GIS database that produced relevant thematic maps representing exclusion criteria. Accordingly, marine areas not satisfying the examined exclusion criteria (i.e., EMAs) were determined and are considered for further evaluation $\left(2^{\text {nd }}\right.$ and $3^{\text {rd }}$ phases of the present site-selection process). In this phase, the processing of all data and the 
creation of thematic maps associated with the exclusion criteria were carried out by GIS and specifically with the support of the ArcGis 10.4 software.

Regarding the exclusion criteria, those were defined based on the available literature (e.g., [11,26-31]). In addition, both the special characteristics of the study area and the relevant provisions and policies of the Greek Specific Framework for the Spatial Planning and Sustainable Development for the Renewable Energy Sources (SFSPSD-RES) [32] were considered. Based on the above, ten exclusion criteria (EC1-EC10) were finally selected (Table 1).

Table 1. Exclusion criteria for OWF siting in Greece.

\begin{tabular}{|c|c|c|c|c|}
\hline & ID & Description & Unsuitable Areas & Source \\
\hline \multirow{5}{*}{$\begin{array}{l}\text { Utilization } \\
\text { restrictions }\end{array}$} & EC1 & $\begin{array}{l}\text { Military Exercise Areas } \\
\text { (MEA) }\end{array}$ & $\begin{array}{l}\text { All marine areas that are utilized for the } \\
\text { implementation of periodical and/or } \\
\text { special military operations }\end{array}$ & {$[11,26,33-40]$} \\
\hline & EC2 & $\begin{array}{l}\text { Areas to be licensed for } \\
\text { Exploration and } \\
\text { Exploitation of } \\
\text { Hydrocarbons (AEEH) }\end{array}$ & $\begin{array}{l}\text { All marine areas licensed for exploration } \\
\text { and exploitation of hydrocarbons }\end{array}$ & {$[11,28-30,41]$} \\
\hline & EC3 & $\begin{array}{l}\text { Offshore Marine } \\
\text { Renewables Energies } \\
\text { Locations (OMREL) }\end{array}$ & $\begin{array}{l}\text { Project proposals that are either under } \\
\text { evaluation, installation, operational, } \\
\text { production license or rejected }\end{array}$ & {$[11,31]$} \\
\hline & EC4 & $\begin{array}{l}\text { Marine Protected Areas } \\
\text { (MPA) }\end{array}$ & All marine Natura 2000 sites & {$[10,11,26,33,37-39,42-46]$} \\
\hline & EC5 & Navigation Routes (NR) & $\begin{array}{c}\text { All navigation routes (cruise ships, cargo } \\
\text { ships and passenger ships) }\end{array}$ & {$[26,33,35,36,38,41,46]$} \\
\hline \multirow{5}{*}{$\begin{array}{l}\text { Economic } \\
\text { and technical } \\
\text { restrictions }\end{array}$} & EC6 & Wind Velocity (WV) & All marine areas with mean wind $<6 \mathrm{~m} / \mathrm{s}$ & {$[11,27-31,41]$} \\
\hline & EC7 & Water Depth (WD) & All marine areas with water depth $>500 \mathrm{~m}$ & {$[11,27-31,41]$} \\
\hline & EC8 & Distance from Shore (DS) & $\begin{array}{l}\text { All marine areas with distance }<20 \mathrm{~km} \text { and } \\
\qquad>200 \mathrm{~km} \text { from the shore }\end{array}$ & {$[11,27-31,41]$} \\
\hline & EC9 & Distance from Ports (DP) & $\begin{array}{l}\text { All marine areas with distance }>100 \mathrm{~km} \\
\text { from ports and water depth }>10 \mathrm{~m} \text { in terms } \\
\text { of draft requirements; all marine areas near } \\
\text { ports and water depth }<10 \mathrm{~m} \text { in terms of } \\
\text { draft requirements }\end{array}$ & {$[39,47,48]$} \\
\hline & EC10 & $\begin{array}{c}\text { Farm minimum required } \\
\text { area (FMRA) }\end{array}$ & All marine areas with surface area $<5 \mathrm{~km}^{2}$ & - \\
\hline
\end{tabular}

\subsubsection{Public Participation through an Online Questionnaire Survey ( $2^{\text {nd }}$ Phase)}

In the $2^{\text {nd }}$ phase, the public participated actively in the OWFs site-selection process through an appropriate designed OQS. Specifically, the aim of the OQS was twofold: (i) to record the public preferences on the significance of the six evaluation criteria (C1-C6) (Table 2), and (ii) to measure the degree of suitability of each EMA concerning OWF siting according to participants' (public) judgments. Thus, the processing of the public replies provided the quantification of the relative weights of: (i) the evaluation criteria and (ii) the EMAs with respect to the SA evaluation criterion (C6 in Table 2).

The OQS consisted of three distinctive sections (Figure 2). The $1^{\text {st }}$ section (personal information) aimed at collecting personal/demographic information of the participants (e.g., age, educational level, profession, relevance of the profession with the energy sector, place of residence). The $2^{\text {nd }}$ section of the OQS focused on the comparative assessment of the six evaluation criteria (C1-C6, Table 2). Accordingly, the participants were asked to state their preference in relation to these criteria, using a nine-point Likert scale (1-non important to 9 -extremely important). Finally, in the $3^{\text {rd }}$ section of the OQS, which was related to the SA evaluation criterion (C6 in Table 2), the participants declared their opinion 
on the relative priority of EMAs (as obtained from the $1^{\text {st }}$ phase of the site-selection process) by performing appropriate comparisons. In this regard, a scale of numbers, known as the Saaty's scale, was deployed to indicate the pairwise importance of the different EMAs. This scale linearly varies from 1 to 9 , indicating respectively, equal importance to extremely more importance $[49,50]$.

Table 2. Evaluation criteria for OWF siting in Greece.

\begin{tabular}{|c|c|c|c|c|}
\hline ID & Name & Description & Objective & $\begin{array}{l}\text { Preference Categories/ } \\
\text { Groups (in Order of } \\
\text { Preference) }\end{array}$ \\
\hline $\mathrm{C1}$ & Wind Velocity (WV) & $\begin{array}{l}\text { WV considers the wind speed at the hub heights of } \\
10 \mathrm{~m} \text { and is related to the economic viability of an OWF }\end{array}$ & maximize & $\begin{array}{l}6.5-7.5 \mathrm{~m} / \mathrm{s} \\
6.0-6.5 \mathrm{~m} / \mathrm{s}\end{array}$ \\
\hline $\mathrm{C} 2$ & Water Depth (WD) & $\begin{array}{l}\text { WD is essential to identify the suitability of OWF } \\
\text { technical solutions and, thus, it is related to an OWF } \\
\text { investment costs }\end{array}$ & minimize & $\begin{array}{c}0-20 \mathrm{~m} \\
20-60 \mathrm{~m} \\
60-300 \mathrm{~m} \\
300-500 \mathrm{~m}\end{array}$ \\
\hline $\mathrm{C} 3$ & $\begin{array}{l}\text { Distance from Shore } \\
\text { (DS) }\end{array}$ & $\begin{array}{l}\text { DS is related to the cost of the submarine cabling for } \\
\text { achieving the connection to the onshore electrical grid, } \\
\text { as well as to operational and maintenance costs }\end{array}$ & minimize & $\begin{array}{c}20-50 \mathrm{~km} \\
50-100 \mathrm{~km} \\
100-150 \mathrm{~km} \\
150-200 \mathrm{~km}\end{array}$ \\
\hline $\mathrm{C} 4$ & Population Served (PS) & $\begin{array}{l}\text { PS reveals the number of people (within a } 50 \mathrm{~km} \\
\text { distance around the OWF location) that could be } \\
\text { potentially benefited by an OWF in terms of } \\
\text { contribution to the coverage of the energy demands }\end{array}$ & maximize & $\begin{array}{c}110,000-145,000 \\
80,000-110,000 \\
50,000-80,000 \\
30,000-50,000 \\
3000-30,000\end{array}$ \\
\hline $\mathrm{C} 5$ & $\begin{array}{l}\text { Connection to Local } \\
\text { Electrical Grid (CLEG) }\end{array}$ & $\begin{array}{l}\text { CLEG evaluates the proximity of the OWF to the } \\
\text { existing onshore local electrical grid of high capacity }\end{array}$ & maximize & $\begin{array}{c}150,000-220,000 \mathrm{~kW} \\
90,000-150,000 \mathrm{~kW} \\
45,000-90,000 \mathrm{~kW} \\
15,000-45,000 \mathrm{~kW} \\
4500-15,000 \mathrm{~kW}\end{array}$ \\
\hline C6 & Social Acceptance (SA) & SA estimates the citizens' preferences for EMAs & maximize & $\begin{array}{l}\text { 9: extremely important } \\
\text { 7: very important } \\
\text { 5: important } \\
\text { 3: slight important } \\
\text { 1: non important }\end{array}$ \\
\hline
\end{tabular}

\subsubsection{Evaluation Phase ( $3^{\text {rd }}$ Phase)}

In the $3^{\text {rd }}$ phase, the EMAs, as obtained from the $1^{\text {st }}$ phase of site-selection process, were evaluated and ranked. For this purpose, AHP was applied. The relative weights of the evaluation criteria were retrieved from the $2^{\text {nd }}$ phase of the site-selection process according to public preferences. On the other hand, the pairwise comparisons of the EMAs for the C1-C5 evaluation criteria were carried out according to the categorization of each evaluation criterion in preference groups (Table 2) based on their actual values. In the case of the SA evaluation criterion (C6), the corresponding relative weights of the EMAs were obtained from the OQS according to public preferences. Based on the overall ranking of the EMAs, the most suitable EMA for OWF siting in the Greek marine environment was defined and proposed. Finally, a sensitivity analysis on the AHP weights was performed to reveal the impact of varying evaluation criteria weights to the final outcome. It should be noted that sensitivity analysis is important and necessary to examine the degree of uncertainty that appears in the decision-making processes. For this purpose, four, additional to the baseline scenario, new sets of weights (scenarios) were used. Scenario 1 was the baseline scenario and considered the responses of all participants in the OQS. The second scenario (Scenario 2) considered equal weights to all evaluation criteria, while the rest three scenarios consider the preferences of three different focus groups participated 
in the OQS: (i) engineers in the RES sector (Scenario 3), (ii) engineers (Scenario 4) and (iii) islands' residents (Scenario 5).

\section{Results and Discussion}

In the following sub-Sections, the results of the present study are presented and discussed. Initially, the EMAs for OWF siting as obtained from the first phase of the proposed methodological site-selection process (Figure 2) are cited. Next, we focus on the outcomes of the OQS (second phase of the proposed site-selection process, Figure 2), while, finally, we present the results of the AHP application (third phase of the proposed site-selection process, Figure 2) along with those of the sensitivity analysis.

\subsection{Determination of EMAs}

The identification of unsuitable marine areas for OWFs siting in Greece and, accordingly, the determination of the EMAs are achieved by deploying the thematic maps of the exclusion criteria (Table 1).

Considering utilization restrictions, Figure 3a shows the superimposed in GIS thematic maps of the relevant exclusion criteria EC1-EC5. It can be seen that MEA (EC1), AEEH (EC2) and NV (EC5) impose significant utilization restrictions in the study area, while OMREL (EC3) and MPA (EC4) are mainly found in the North-East and North Aegean, respectively. As for the rest exclusion criteria related to technical and economic restrictions, indicatively the thematic maps of WV (EC6) and WD (EC7) are shown in Figure 3b,c, respectively. In each thematic map, the data were grouped according to the preference groups of Table 2. Marine areas in Greece, where the WV is above the limit of $6 \mathrm{~m} / \mathrm{s}$ (Figure 3b), are identified in a lengthwise zone extended from North-central to central Aegean, as well as West and East of Crete. As for the WD (Figure 3c), the relevant thematic maps reveal the existence of deep waters in many locations of the study area.

By superimposing the thematic maps of Figure 3, along with those of EC8-EC10, the EMAs for the siting of OWFs in Greece are determined. In total, thirteen EMAs of a total area of $2468.39 \mathrm{~km}^{2}$ were identified, as shown in Figure 4. The main characteristics of those areas are included in Table 3. The first seven EMAs representing $91.3 \%$ of the total EMAs area are located offshore of Skiros, Lesvos and Chios islands in North Aegean. The subsequent EMA (EMA8) is situated in central Aegean and it covers $0.7 \%$ of the $2468.39 \mathrm{~km}^{2}$. The remaining $8.0 \%$ of the total EMAs area is represented by EMA9-EMA13, which are located in South-East Aegean, offshore of Kos, Rhodes and Crete islands.

Table 3. Characteristics of EMAs for the siting of OWFs in Greece.

\begin{tabular}{ccc}
\hline No. & Location & Area $\mathbf{( k m}^{\mathbf{2}} \mathbf{~}$ \\
\hline 1 & East of Skiros & 1343 \\
2 & South-East of Skiros & 15.03 \\
3 & South-West of Lesvos & 554.20 \\
4 & South-West of Lesvos & 21.96 \\
5 & East of Chios & 62.73 \\
6 & South-East of Chios & 192.66 \\
7 & South-South-East of Chios & 64.76 \\
8 & North-East of Amorgos & 16.80 \\
9 & North-West of Kos & 39.01 \\
10 & South-West of Rhodes & 14.66 \\
11 & South-South-West of Rhodes & 58.89 \\
12 & East-North-East of Crete & 17.94 \\
13 & East of Crete & 66.75 \\
\hline
\end{tabular}




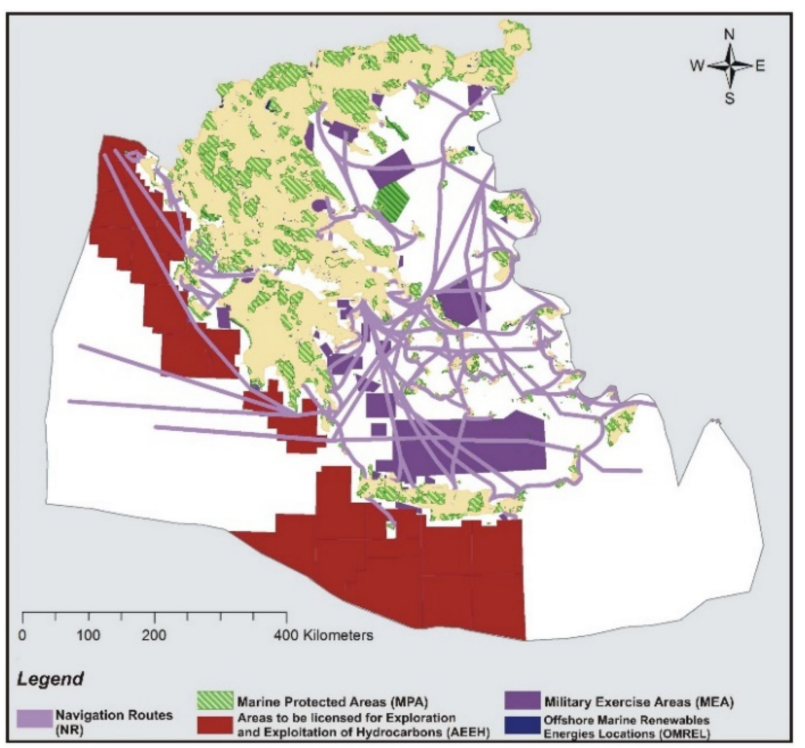

(a)

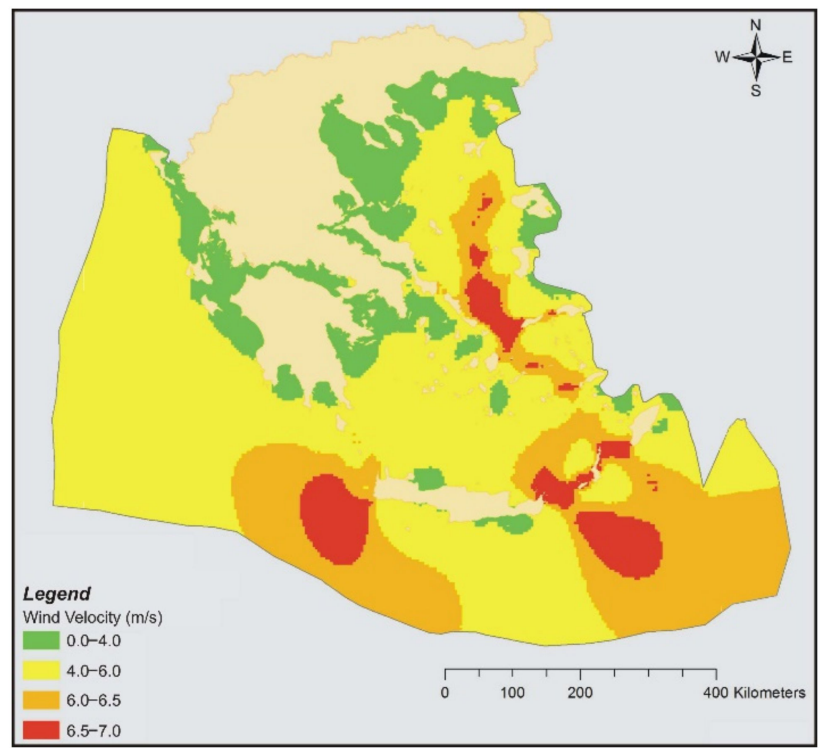

(b)

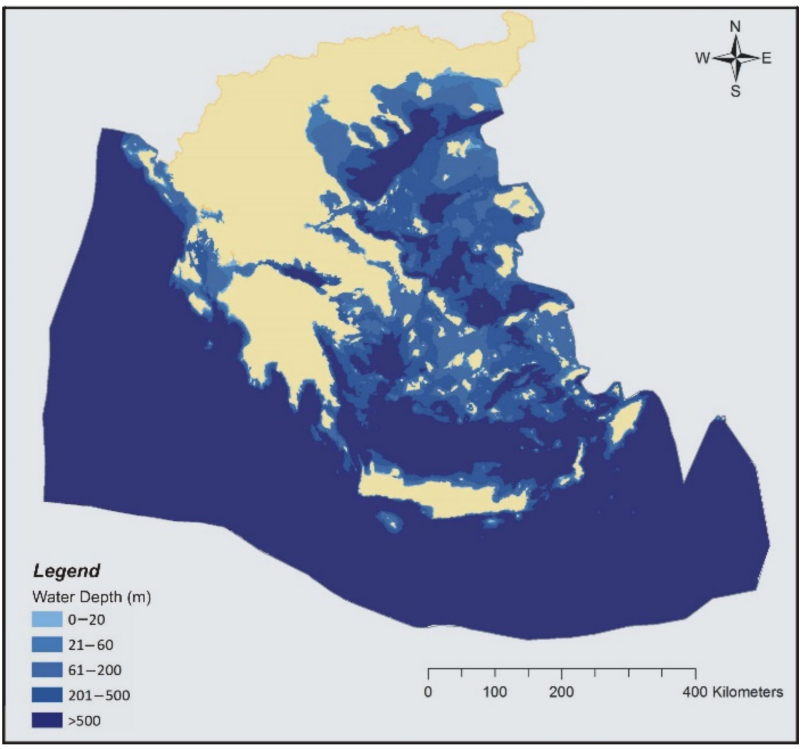

(c)

Figure 3. Thematic maps of: (a) Utilization restrictions (EC1-EC5); (b) WV (EC6); (c) WD (EC7).

\subsection{OQS Results}

Within the OQS, 122 questionnaires fully completed by the public (Greek residents) were acquired. Among the total number of the OQS participants, 77 (63\%) were engineers of various specialties, $73(\sim 60 \%)$ were engineers of various specialties working though only in the RES sector and $11(9 \%)$ were residents of Greek islands.

Starting with the comparative assessment of the six evaluation criteria (C1-C6, Table 2), the answers of the public acquired in the second section of the OQS were adequately postprocessed in order to quantify the relative importance (relative weights) of those criteria with respect to the overall goal of the present site-selection process. The corresponding results are shown in Figure 5. According to the public opinion, C1 (WV) and C2 (WD) present the most important evaluation criteria for the OWF siting, since these two criteria have obtained the largest relative weights (21\% and $17.4 \%$, respectively) among all examined evaluation criteria. C3 (DS), having a relative weight of $16.1 \%$, corresponds to the third most important evaluation criterion, followed in decreasing order of preference by C4 (PS), C5 (CLEG) and, finally, by C6 (SA). The relative weights of the three latter criteria do not 
differ significantly and they sup up to a total percentage of $45.5 \%$. Based on all the above, it can be concluded that, according to the public participated in the OQS, the suitability of a marine area for the siting of an OWF is mainly affected by three techno-economic evaluation criteria (i.e., WV, WD and DS). On the other hand, SA (degree of suitability of an EMA according to public judgment) was ranked as the less important evaluation criterion. However, the public preferences revealed that SA can be considered of almost equal importance when compared with specific techno-economic criteria (i.e., PS and CLEG).

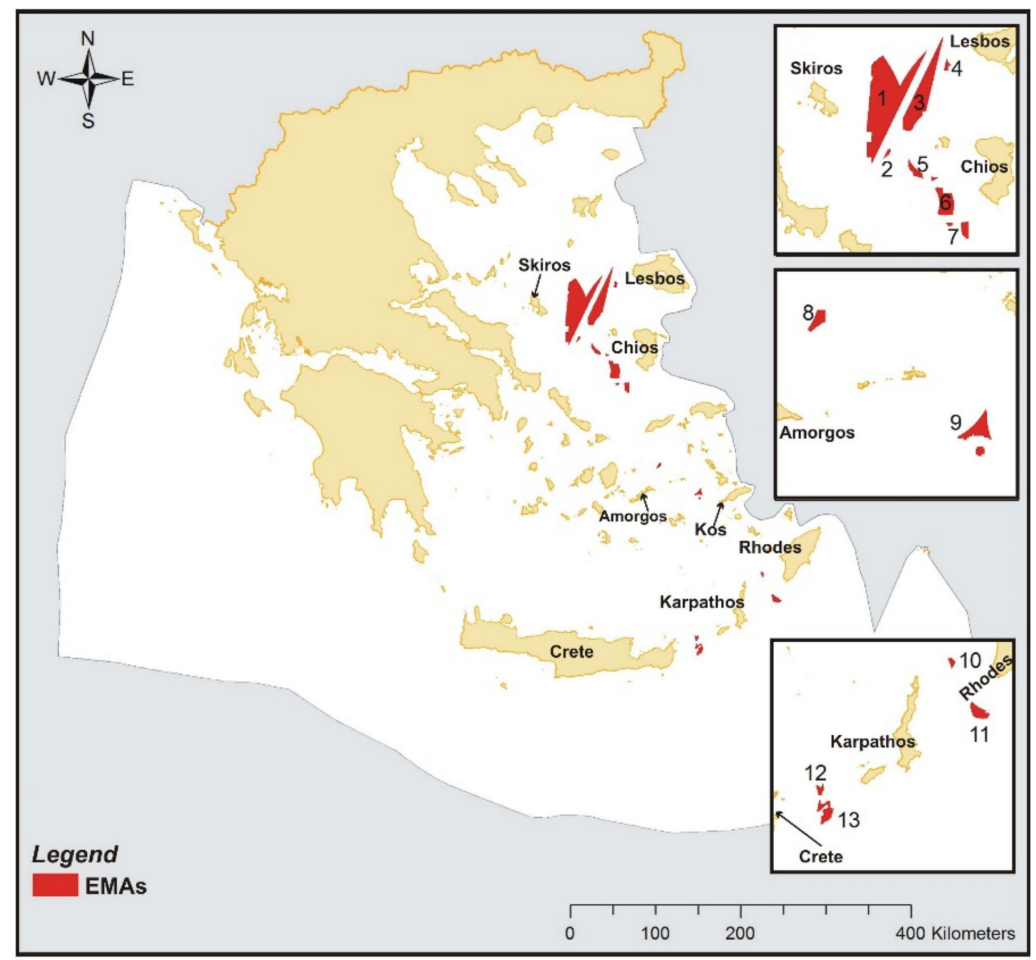

Figure 4. EMAs for the siting of OWFs in Greece.

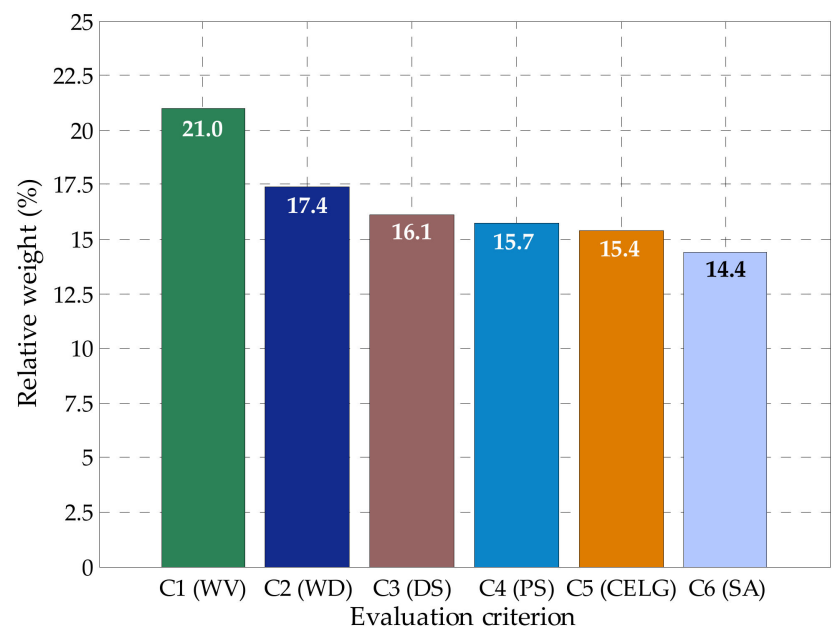

Figure 5. Relative weights of the evaluation criteria C1-C6 according to public preferences.

Moving on to the public opinion on the relative priority of the EMAs (Table 3), the corresponding results acquired from the third section of the OQS are shown in Figure 6. Specifically, the thematic map of Figure 6a displays the ranking of the EMAs according to the public preferences, while the bar plot of Figure $6 \mathrm{~b}$ shows the relative weights (relative importance) of EMAs with respect to the SA evaluation criterion (C6). It can be seen that 
EMA10, EMA12 and EMA13 located in South-East Aegean (South-West of Rhodes, EastNorth-East of Crete and East of Crete, respectively) were considered by the public as the most important marine areas for the OWF siting in Greece. Accordingly, they correspond to the most socially accepted EMAs. EMA1, EMA3, EMA5 and EMA6 (North Aegean) are ranked in the second position in terms of social acceptance, followed by EMA4, EMA7, EMA8 and EMA11 (third raking position), EMA9 (fourth raking position) and, finally, by EMA2 (fifth raking position).

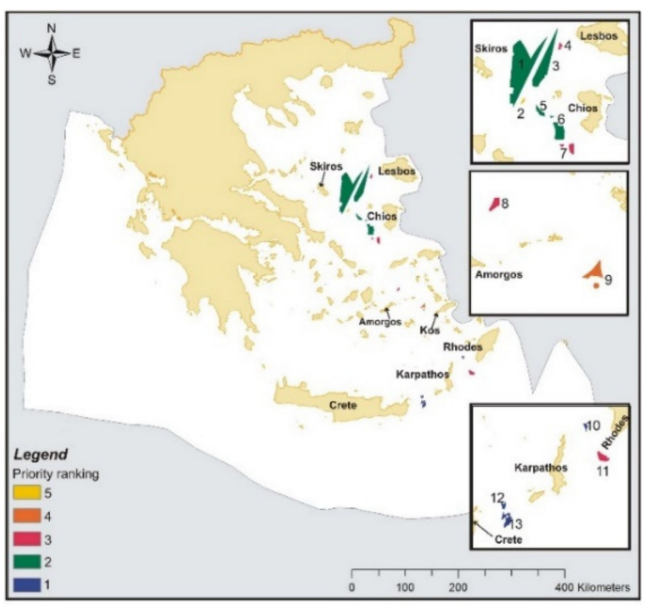

(a)

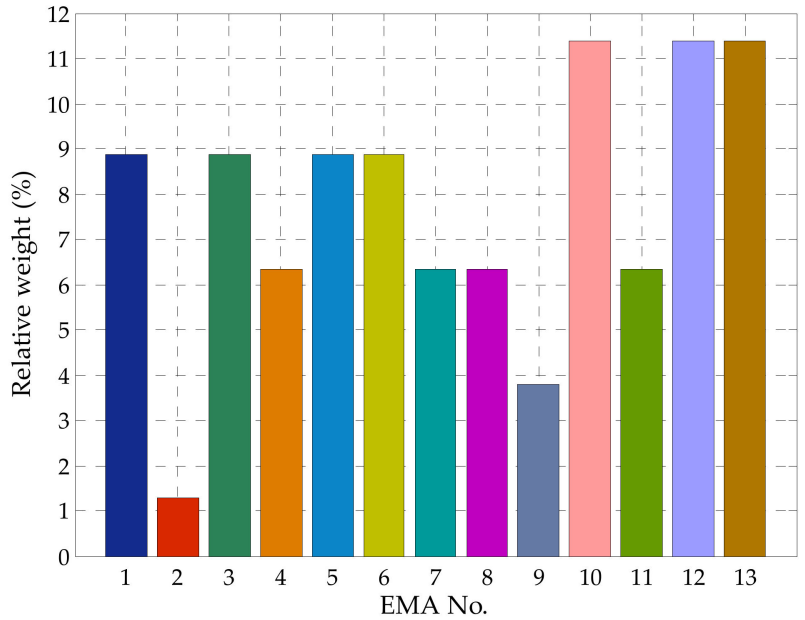

(b)

Figure 6. (a) Ranking of EMAs according to public preferences; (b) Relative weights of EMAs with respect to SA (C6).

\subsection{Evaluation and Ranking of EMAs}

In addition to the relative weights of Figures 5 and $6 \mathrm{~b}$, the application of AHP in terms of evaluating and ranking the 13 EMAs of Table 3 requires the quantification of the relative weights of the EMAs with respect to C1-C5. The corresponding results, obtained through appropriate pairwise comparisons of the EMAs as explained in Section 2.2.3, are shown in Figure 7 . It is noted that the consistency of the $13 \times 13$ pairwise comparisons for each of the $\mathrm{C} 1-\mathrm{C} 5$ evaluation criterion was verified by obtaining a consistent ratio value smaller than 0.1 [51].

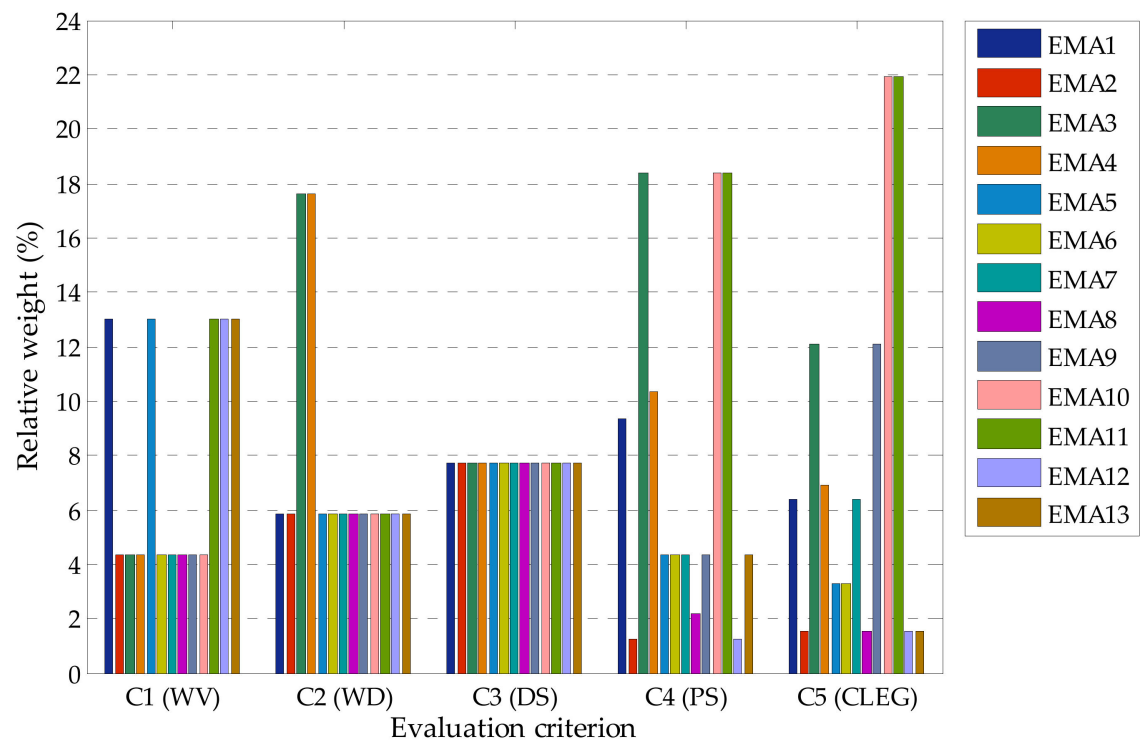

Figure 7. Relative weights of EMAs with respect to $\mathrm{C} 1-\mathrm{C} 5$. 
Regarding the offshore wind resource, EMA1, EMA5 and EMA11-EMA13 correspond to the most preferable EMAs in terms of $\mathrm{C} 1$, since in those areas the $\mathrm{WV}$ obtains the largest values (in the range of 6.5-7.5 m/s) among all examined EMAs. Considering the evaluation criterion C2 (WD), EMA3 and EMA4 are characterized by intermediate WD conditions (in the range of 21-60 m) contrary to the rest EMAs and, thus, they represent the two most preferable alternatives. All EMAs are considered of equal importance with respect to the evaluation criterion C3 (DS), since they all belong to the same DS preference group (21-50 km). As for evaluation criteria C4 and C5, the preference order varies significantly among the various EMAs depending upon the location of each alternative, with EMA3, EMA10, EMA11 and EMA10, EMA11 corresponding to the most preferable areas in terms of $\mathrm{C} 4$ and $\mathrm{C} 5$ respectively.

By combing the relative weights of EMAs with respect to C1-C6 (Figures $6 \mathrm{~b}$ and 7) with the relative weights of the evaluation criteria with respect to the goal of the present site-selection process (Figure 5), the 13 EMAs are evaluated and ranked. The corresponding results are included in Table 4.

Table 4. Prioritization of EMAs for the siting of OWFs in Greece.

\begin{tabular}{ccc}
\hline Ranking & Decision Alternative (EMA) & Preference Percentage (\%) \\
\hline 1 & EMA11 & 12.2 \\
2 & EMA3 & 11.3 \\
3 & EMA10 & 11.1 \\
4 & EMA4 & 8.8 \\
5 & EMA1 & 8.7 \\
6 & EMA13 & 7.6 \\
7 & EMA5 & 7.5 \\
8 & EMA12 & 7.1 \\
9 & EMA9 & 6.3 \\
10 & EMA7 & 5.8 \\
11 & EMA6 & 5.7 \\
12 & EMA8 & 4.7 \\
\hline
\end{tabular}

EMA11, located South-South-West of Rhodes (Figure 4), corresponds to the most suitable area for the siting of OWFs in Greece (preference percentage equal to $12.2 \%$ ). This is mainly attributed to the existence of large WV (in the range of $6.5-7.5 \mathrm{~m} / \mathrm{s}$ ) in this area, as well as to: (i) the close proximity of EMA11 to local grids of high capacity (e.g., local grid in Rhodes) and (ii) the potential of this area to serve a large population. The latter potential combined with the existence of small water depths (in the range of 21-60 m) drive mainly the ranking of EMA3, located South-West of Lesvos (Figure 4), as the second top choice (preference percentage equal to 11.3\%). EMA10 situated South-West of Rhodes (Figure 4) corresponds to the third top choice (preference percentage equal to $11.1 \%$ ) attributed to: (i) the existence of good features of EMA10 with regard to PS and CLEG, as in the case of EMA11 and (ii) the identification of EMA10 as one of the most socially accepted EMAs. Finally, EMA4 (South-West of Lesvos, Figure 4) and EMA1 (East of Skiros, Figure 4) are ranked in the fourth and fifth position, respectively (preference percentage equal to $8.8 \%$ and $8.7 \%$, respectively). The above ranking is mainly driven by the existence of WD in the range of 21-60 m for EMA4 and of WV in the range of 6.5-7.5 m/s for EMA1, combined with the potential of both areas to serve a large population.

\subsection{Sensitivity Analysus Results}

Figure 8 shows the relative weights of the evaluation criteria $\mathrm{C} 1-\mathrm{C} 6$ for the five scenarios deployed in the sensitivity analysis. It is recalled that Scenario 1 is defined as the baseline scenario and takes into account all participants' responses in the OQS. Accordingly, the relative weights of Scenario 1 coincide with those of Figure 5. In the case of Scenario 2, all evaluation criteria were assigned the same weight, equal to $16.7 \%$. As for the last three 
scenarios, the weights of $\mathrm{C} 1-\mathrm{C} 6$ were defined based on the preferences of different focus groups participated in the OQS, corresponding to: (i) engineers working only in the RES sector (first focus group, Scenario 3), (ii) engineers (second focus group, Scenario 4) and (iii) islands' residents (third focus group, Scenario 5).

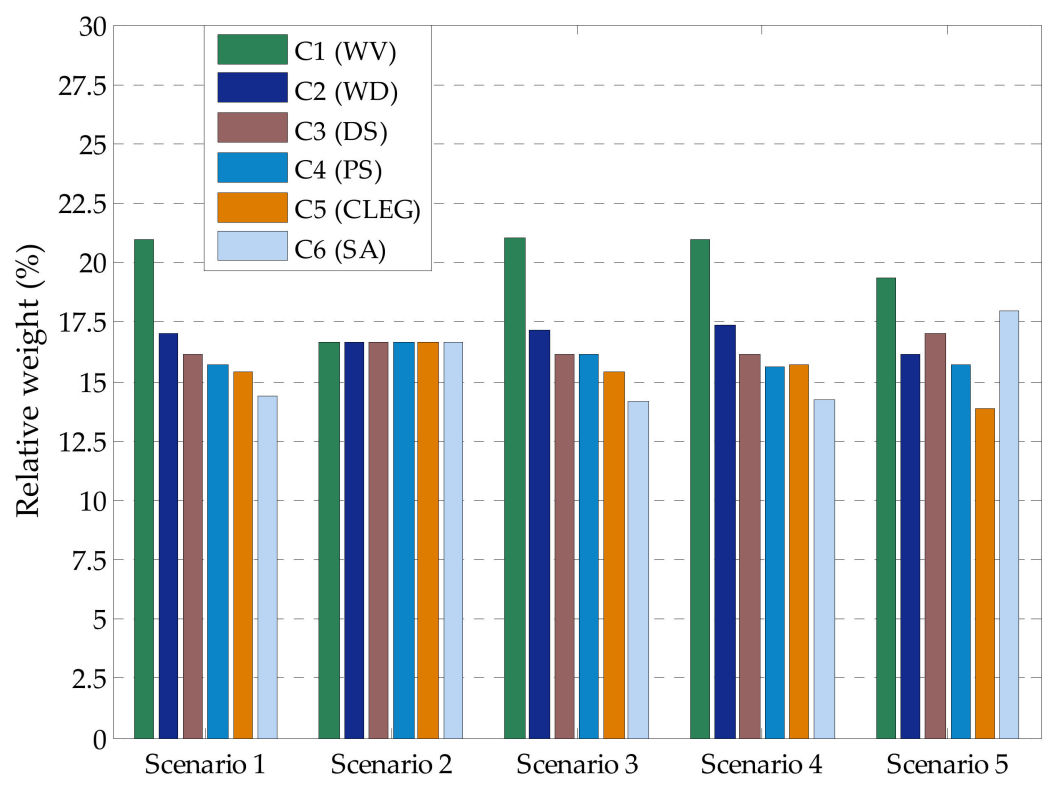

Figure 8. Relative weights of $\mathrm{C} 1-\mathrm{C} 6$ for the five scenarios of the sensitivity analysis.

In the case of Scenarios 3 and 4, the relative weights of C1-C6 are quite similar with those of the baseline scenario. Accordingly, the first and second focus groups consider two techno-economic evaluation criteria (i.e., WV and WD) as the most important ones for the OWF siting, while their responses ranked SA as the less important evaluation criterion. In the case of Scenario 5, WV corresponds again to the most important evaluation criterion. However, and contrary to Scenarios 1, 3 and 4, the islands' residents consider the SA criterion as the second most important one. It is also worth noting that all three focus groups ranked in the third position the techno-economic criterion DS (C3), while the preferences of the islands' residents revealed that PS (C5) can be considered of almost equal importance when compared to WD (C2). Based on all the above, it can be concluded that, by focusing on Scenario 5, only on the preferences of the islands' residents, the significant differences of the C1-C6 relative importance are introduced compared to Scenarios 1, 3 and 4 .

By applying AHP for the C1-C6 relative weights of Scenarios 2-5, the 13 EMAs were evaluated and ranked again. The corresponding results are included in Table 5, where also the results of the baseline scenario (Scenario 1) coinciding with those of Table 4 are included for comparison purposes. It can be seen that the priority ranking of the EMAs in the case of Scenario 3 and 4 shows no differences compared with the baseline scenario. The same holds true for Scenario 2, except of EMA3 and EMA10, which have been ranked in a reverse order compared to Scenario 1. In the case of Scenario 5, the existence of different C1-C6 relative weights (Figure 8) introduces some noticeable differences in the ranking of EMAs. Specifically, although EMA11 (South-South-West of Rhodes, Figure 4), EMA3 (South-West of Lesvos, Figure 4) and EMA10 (South-West of Rhodes, Figure 4) present still the three top choices, EMA10, corresponding to one of the most socially accepted EMAs (Figure 6b), was ranked in the first position, followed by EMA11 and then by EMA3. Another noticeable difference is the ranking of the rest two most socially accepted areas (EMA12 and EMA13 in Figure $6 b$ ) at higher positions compared to Scenario 1. In detail, EMA13 (East of Crete, Figure 4) enters at the top of the five choices and is ranked in the fourth position, while EMA12 (East-North-East of Crete) is ranked in the sixth position. The above lead in turn to 
the ranking of EMA4 (4th top choice in Scenarios 1-4) in the seventh position in the case of Scenario 5.

Table 5. Prioritization of EMAs for the siting of OWFs in Greece for different scenarios.

\begin{tabular}{|c|c|c|c|c|c|}
\hline \multirow{2}{*}{ Ranking } & \multicolumn{5}{|c|}{ EMA (Preference Percentage) } \\
\hline & Scenario 1 & Scenario 2 & Scenario 3 & Scenario 4 & Scenario 5 \\
\hline 1 & EMA11 (12.2\%) & EMA11 (12.2\%) & EMA11 (12.2\%) & EMA11 (12.2\%) & EMA10 $(12.1 \%) *$ \\
\hline 2 & EMA3 (11.3\%) & EMA10 $(11.6 \%) *$ & EMA3 (11.3\%) & EMA3 (11.2\%) & EMA11 $(11.3 \%) *$ \\
\hline 3 & EMA10 (11.1\%) & EMA3 $(11.5 \%) *$ & EMA10 (11.1\%) & EMA10 $(11.1 \%)$ & EMA3 $(11.0 \%) *$ \\
\hline 4 & EMA4 (8.8\%) & EMA4 $(8.9 \%)$ & EMA4 (8.8\%) & EMA4 (8.8\%) & EMA13 $(8.8 \%) *$ \\
\hline 5 & EMA1 (8.7\%) & EMA1 (8.5\%) & EMA1 (8.7\%) & EMA1 (8.7\%) & EMA1 $(8.5 \%)$ \\
\hline 6 & EMA13 (7.6\%) & EMA13 $(7.3 \%)$ & EMA13 (7.5\%) & EMA13 (7.5\%) & EMA12 $(8.3 \%) *$ \\
\hline 7 & EMA5 $(7.5 \%)$ & EMA5 $(7.2 \%)$ & EMA5 $(7.4 \%)$ & EMA5 $(7.4 \%)$ & EMA4 $(8.3 \%) *$ \\
\hline 8 & EMA12 (7.1\%) & EMA12 (6.8\%) & EMA12 $(7.0 \%)$ & EMA12 (7.1\%) & EMA5 $(7.3 \%) *$ \\
\hline 9 & EMA9 $(6.3 \%)$ & EMA9 $(6.4 \%)$ & EMA9 $(6.3 \%)$ & EMA9 $(6.3 \%)$ & EMA9 $(5.8 \%)$ \\
\hline 10 & EMA7 (5.8\%) & EMA7 (5.8\%) & EMA7 (5.7\%) & EMA7 (5.7\%) & EMA6 $(5.6 \%) *$ \\
\hline 11 & EMA6 (5.7\%) & EMA6 (5.7\%) & EMA6 (5.6\%) & EMA6 (5.6\%) & EMA7 $(5.3 \%) *$ \\
\hline 12 & EMA8 (4.7\%) & EMA8 (4.7\%) & EMA8 (4.7\%) & EMA8 (4.7\%) & EMA8 (4.3\%) \\
\hline 13 & EMA2 (3.8\%) & EMA2 (3.7\%) & EMA2 (3.8\%) & EMA2 (3.8\%) & EMA2 (3.7\%) \\
\hline
\end{tabular}

${ }^{*}$ Different ranking compared to Scenario 1 .

\section{Conclusions}

In the present paper, a methodological site-selection process is developed and applied in order to identify the most suitable marine areas for deploying OWFs in Greece according to the public opinion. The process is based on the combined use of AHP and GIS with an OQS, where the citizens' preferences are gathered and handled. Furthermore, social acceptance is considered explicitly as an evaluation criterion along with five more criteria representing techno-economic factors.

The results of the present investigation demonstrated the existence of thirteen EMAs for the siting of OWFs in the Greek marine environment, located in North Aegean (seven EMAs), in central Aegean (one EMA) and in South-East Aegean (five EMAs). It should be noted that some marine areas characterized by a vast wind potential were excluded from the analysis due to spatial constraints resulting from very deep-water conditions and/or specific utilization restrictions related mainly to military operations and hydrocarbons exploration/exploitation.

According to all participants' responses in the OQS (baseline scenario), three technoeconomic criteria (wind velocity, water depth and distance from shore) represent the most important evaluation criteria for the OWFs siting. Social acceptance was ranked as the less important evaluation criterion, having, though, an almost equal importance when compared with other techno-economic criteria (population served and proximity to a local grid). Among all the thirteen EMAs, the answers of the OQS revealed that three of them (total area of $99.35 \mathrm{~km}^{2}$ ), located in South-East Aegean offshore of Rhodes and Crete, represent the most socially accepted marine areas, followed by four EMAs (total area of $2152.59 \mathrm{~km}^{2}$ ) situated in North Aegean.

The marine area, located South-South-West offshore of Rhodes (size area equal to $58.89 \mathrm{~km}^{2}$ ), corresponds to the most suitable area for the siting of OWFs in Greece. This is mainly attributed to the existence of a large wind potential in this EMA, along with: (i) the close proximity of this area to a local grid of high capacity and (ii) the potential of this area to serve a large population. The latter potential combined with the existence of small water depths resulted to the ranking of the offshore area South-West of Lesvos (size area equal to $554.20 \mathrm{~km}^{2}$ ) in North Aegean as the second top choice. Finally, the marine area, located South-West offshore of Rhodes (size area equal to $14.66 \mathrm{~km}^{2}$ ), corresponding to one of the most socially accepted EMAs and having good features as far as the served population and the proximity to a local grid, presents the third top choice for the siting of OWFs in Greece. 
Regarding the sensitivity analysis, the preferences of specific focus groups that participated in the OQS were considered separately for quantifying the evaluation criteria's relative weights. The corresponding results demonstrated that the priority ranking of the EMAs in the baseline scenario does not change, when the groups are formed according to the participants' specialization (engineers or engineers working explicitly in the RES sector). However, when the preferences of the islands' residents are only taken into account, the priority ranking of the EMAs changes compared with the baseline scenario. The most noticeable difference is that the three most socially accepted sites, located in South-East Aegean offshore of Rhodes and Crete, are ranked at higher positions.

The results of the present paper illustrate the potential of deploying OWFs in Greece, supporting, thus, the fulfillment of the Greek national energy targets in the near future. They also highlight the importance of the active public engagement within the relevant site-selection process.

Along these lines and acknowledging as a potential limitation of our work the size of the OQS sample with respect to the overall Greek population, the present investigation could be further extended by focusing on the involvement of a larger number of islands' residents, directly affected by OWFs installations, and/or of specific target groups (e.g., fishermen, tourism representatives, environmental non-profit organizations' representatives, investors etc.) in the OWFs site-selection process. Future research could also include the identification of the most suitable support structures in the thirteen EMAs. Furthermore, the proposed methodology could be easily adapted to and applied for any other type of spatial constraints or techno-economic, environmental and social factors that could affect the decision-making process, towards the sustainable exploitation of the vast offshore wind potential.

Author Contributions: Conceptualization, E.L. and D.G.V.; methodology, E.L., D.G.V. and A.L.; software, A.L.; formal analysis, A.L.; investigation, A.L.; data curation, A.L.; visualization, E.L., D.G.V. and A.L.; writing — original draft preparation, E.L. and D.G.V.; writing—review and editing, E.L., D.G.V. and A.L.; supervision, E.L. and D.G.V. All authors have read and agreed to the published version of the manuscript.

Funding: This research received no external funding.

Institutional Review Board Statement: Not applicable.

Informed Consent Statement: Not applicable.

Acknowledgments: The present research was implemented within the framework of the iGrowLabs action supported by the Aristotle University of Thessaloniki, the Technical Chamber of Greece and the Association of Information Technology Companies of Northern Greece. The authors would like to thank S.N. Siagas and D. Fotopoulou, responsible of the iGrowLabs action, for providing this opportunity as well as T. Roustanis, S. Tselepis and M. Letsios, of Infodim company for their support in terms of implementing this research.

Conflicts of Interest: The authors declare no conflict of interest.

\section{References}

1. Kaldellis, J.K.; Apostolou, D.; Kapsali, M.; Kondili, E. Environmental and social footprint of offshore wind energy. Comparison with onshore counterpart. Renew. Energy 2016, 92, 543-556. [CrossRef]

2. Rediske, G.; Burin, H.P.; Rigo, P.D.; Rosa, C.B.; Michels, L.; Siluk, J.C.M. Wind power plant site selection: A systematic review. Renew. Sustain. Energy Rev. 2021, 148, 111293. [CrossRef]

3. Villacreses, G.; Gaona, G.; Martínez-Gómez, J.; Jijón, D.J. Wind farms suitability location using geographical information system (GIS), based on multi-criteria decision making (MCDM) methods: The case of continental Ecuador. Renew. Energy 2017, 109, 275-286. [CrossRef]

4. Spyridonidou, S.; Vagiona, D.G. Systematic review of site-selection processes in onshore and offshore wind energy research. Energies 2020, 13, 5906. [CrossRef]

5. Van Haaren, R.; Fthenakis, V. GIS-based wind farm site selection using spatial multicriteria analysis (SMCA): Evaluating the case for New York State. Renew. Sustain. Energy Rev. 2011, 15, 3332-3340. [CrossRef] 
6. Szurek, M.; Blachowski, J.; Nowacka, A. GIS-based method for wind farm location multi-criteria analysis. Mar. Sci. 2014, 21, 65-81. [CrossRef]

7. Atici, K.B.; Simsek, A.B.; Ulucan, A.; Tosun, M.U. A GIS-based multiple criteria decision analysis approach for wind power plant site selection. Util. Policy 2015, 37, 86-96. [CrossRef]

8. Höfer, T.; Sunak, Y.; Siddique, H.; Madlener, R. Wind farm siting using a spatial analytic hierarchy process approach: A case study of the Städteregion Aachen. Appl. Energy 2016, 163, 222-243. [CrossRef]

9. Díaz-Cuevas, P. GIS-based methodology for evaluating the wind-energy potential of territories: A case study from Andalusia (Spain). Energies 2018, 11, 2789. [CrossRef]

10. Vagiona, D.G.; Karanikolas, N.M. A multicriteria approach to evaluate offshore wind farms sitting in Greece. Glob. NEST J. 2012, 14, 235-243. [CrossRef]

11. Vasileiou, M.; Loukogeorgaki, E.; Vagiona, D.G. GIS-based multi-criteria decision analysis for site selection of hybrid offshore wind and wave energy systems in Greece. Renew. Sustain. Energy Rev. 2017, 73, 745-757. [CrossRef]

12. Lombard, A.; Ferreira, S. Residents' attitudes to proposed wind farms in the West Coast region of South Africa: A social perspective from the South. Energy Policy 2014, 66, 390-399. [CrossRef]

13. Dwyer, J.; Bidwell, D. Chains of trust: Energy justice, public engagement, and the first offshore wind farm in the United States Energy Res. Soc. Sci. 2019, 47, 166-176. [CrossRef]

14. Delicado, A.; Figueiredo, E.; Silva, L. Community perceptions of renewable energies in Portugal: Impacts on environment, landscape and local development. Energy Res. Soc. Sci. 2016, 13, 84-93. [CrossRef]

15. Wang, C.-N.; Huang, Y.-F.; Chai, Y.-C.; Nguyen, V.T. A multi-criteria decision making (MCDM) for renewable energy plants location selection in Vietnam under a fuzzy environment. Appl. Sci. 2018, 8, 2069. [CrossRef]

16. Azarova, V.; Cohen, J.; Friedl, C.; Reichl, J. Designing local renewable energy communities to increase social acceptance: Evidence from a choice experiment in Austria, Germany, Italy, and Switzerland. Energy Policy 2019, 132, 1176-1183. [CrossRef]

17. Leiren, M.D.; Aakre, S.; Linnerud, K.; Julsrud, T.E.; Di Nucci, M.-R.; Krug, M. Community Acceptance of Wind Energy Developments: Experience from Wind Energy Scarce Regions in Europe. Sustainability 2020, 12, 1754. [CrossRef]

18. Baban, S.M.J.; Parry, T. Developing and applying a GIS-assisted approach to locating wind farms in the UK. Renew. Energy 2001, 24, 59-71. [CrossRef]

19. Georgiou, A.; Polatidis, H.; Haralambopoulos, D. Wind energy resource assessment and development: Decision analysis for site evaluation and application. Energy Sources Part A Recovery Util. Environ. Eff. 2012, 34, 1759-1767. [CrossRef]

20. Ayodele, T.R.; Ogunjuyigbe, A.S.O.; Odigie, O.; Munda, J.L. A multi-criteria GIS based model for wind farm site selection using interval type-2 fuzzy analytic hierarchy process: The case study of Nigeria. Appl. Energy 2018, 228, 1853-1869. [CrossRef]

21. Ali, S.; Taweekun, J.; Techato, K.; Waewsak, J.; Gyawali, S. GIS based site suitability assessment for wind and solar farms in Songkhla, Thailand. Renew. Energy 2019, 132, 1360-1372. [CrossRef]

22. Mekonnen, A.D.; Gorsevski, P.V. A web-based participatory GIS (PGIS) for offshore wind farm suitability within Lake Erie, Ohio. Renew. Sustain. Energy Rev. 2015, 41, 162-177. [CrossRef]

23. Gorsevski, P.V.; Cathcart, S.C.; Mirzaei, G.; Jamali, M.M.; Ye, X.; Gomezdelcampo, E. A group-based spatial decision support system for wind farm site selection in Northwest Ohio. Energy Policy 2013, 55, 374-385. [CrossRef]

24. Bowman, J.S.; Marker, S.; Keraislands Siotis, P.; Sarna, H. Greece in Depth, Frommer's Greece, 7th ed.; Wiley: Hoboken, NJ, USA, 2010; p. 12.

25. Hellenic Organization of Tourism (HTO). Available online: www.gnto.gov.gr (accessed on 29 November 2021).

26. Mahdy, M.; Bahaj, A.S. Multi criteria decision analysis for offshore wind energy potential in Egypt. Renew. Energy 2018, 118, 278-289. [CrossRef]

27. Ziemba, P.; Watrobski, J.; Ziolo, M.; Karczmarczyk, A. Using the PROSA method in offshore wind farm location problems. Energies 2017, 10, 1755. [CrossRef]

28. Fetanat, A.; Khorasaninejad, E. A novel hybrid MCDM approach for offshore wind farm site selection: A case study of Iran. Ocean Coast. Manag. 2015, 109, 17-28. [CrossRef]

29. Bagocius, V.; Zavadskas, E.K.; Turskis, Z. Sequence determining of construction of the offshore wind farm construction applying permutation method. Ekon. Manag. 2014, 17, 50-61. [CrossRef]

30. Sourianos, E.; Kyriakou, K.; Hatiris, G.A. GIS-based spatial decision support system for the optimum siting of offshore windfarms. Eur. Water. 2017, 58, 337-343.

31. Wu, Y.; Zhang, J.; Yuan, J.; Geng, S.; Zhang, H. Study of decision framework of offshore wind power station site selection based on ELECTRE-III under intuitionistic fuzzy environment: A case of China. Energy Convers. Manag. 2016, 113, 66-81. [CrossRef]

32. Ministry of Environment and Energy. Specific Framework for Spatial Planning and Sustainable Development for Renewable Energy Sources. Available online: https://ypen.gov.gr/wp-content/uploads/2020/11/FEK2464B_2008_RES.pdf (accessed on 1 September 2021).

33. Kim, C.-K.; Jang, S.; Kim, T.Y. Site selection for offshore wind farms in the southwest coast of South Korea. Renew. Energy 2018, 120, 151-162. [CrossRef]

34. Spyridonidou, S.; Vagiona, D.G.; Loukogeorgaki, E. Strategic Planning of Offshore Wind Farms in Greece. Sustainability 2020, 12, 905. [CrossRef] 
35. Emeksiz, C.; Demirci, B. The determination of offshore wind energy potential of Turkey by using novelty hybrid site selection method. Sustain. Energy Technol. Assess. 2019, 36, 100562. [CrossRef]

36. Argin, M.; Yerci, V. The assessment of offshore wind power potential of Turkey. In Proceedings of the 9th International Conference on Electrical and Electronics Engineering (ELECO), Bursa, Turkey, 26-28 November 2015; pp. 966-970.

37. Kim, J.Y.; Kang, K.S.; Oh, K.Y.; Lee, J.S.; Ryu, M.S. A study on the site selection of offshore wind farm around Korean Peninsula. In Proceedings of the 3rd International Conference on Ocean Energy, Bilbao, Spain, 6-8 October 2010; pp. 1-4.

38. Argin, M.; Yerci, V.; Erdogan, N.; Kucuksari, S.; Cali, U. Exploring the offshore wind energy potential of Turkey based on multicriteria site selection. Energy Strategy Rev. 2019, 23, 33-46. [CrossRef]

39. Kim, T.; Park, J.-I.; Maeng, J. Offshore wind farm site selection study around Jeju Island, South Korea. Renew. Energy 2016, 94, 619-628. [CrossRef]

40. Spyridonidou, S.; Vagiona, D.G. Spatial energy planning of offshore wind farms in Greece using GIS and a hybrid MCDM methodological approach. Euro-Mediterr. J. Environ. Integr. 2020, 5, 24. [CrossRef]

41. Christoforaki, M.; Tsoutsos, T. Sustainable siting of an offshore wind park a case in Chania, Crete. Renew. Energy 2017, 109, 624-633. [CrossRef]

42. Gavériaux, L.; Laverrière, G.; Wang, T.; Maslov, N.; Claramunt, C. GIS-based multi-criteria analysis for offshore wind turbine deployment in Hong Kong. Ann. GIS 2019, 25, 207-218. [CrossRef]

43. Stefanakou, A.-A.; Nikitakos, N. A Decision Support Model For Site Selection of Offshore wind Farms. Available online: http:/ / www.promitheasnet.kepa.uoa.gr/images/9th_Conference_2016/Presentations/S4/A-decision-support-model-forsite-selection-of-offshore-windfarms.pdf (accessed on 29 November 2021).

44. Saleous, N.; Issa, S.; Al Mazrouei, J. GIS-based wind farm site selection model offshore Abu Dhabi Emirate, UAE. Int. Arch. Photogramm. Remote Sens. Spat. Inf. Sci. 2016, XLI-B8, 437-441. [CrossRef]

45. Mani Murali, R.; Vidya, P.J.; Modi, P.; Jaya Kumar, S. Site selection for offshore wind farms along the Indian coast. Indian J. Geo Mar. Sci. 2014, 43, 1401-1406.

46. Castro-Santos, L.; Lamas-Galdo, M.I.; Filgueira-Vizoso, A. Managing the oceans: Site selection of a floating offshore wind farm based on GIS spatial analysis. Mar. Policy 2020, 113, 103803. [CrossRef]

47. Yue, C.; Wang, S. Exploring the potential of wind energy for a coastal state. Energy Policy 2009, 37, 3925-3940. [CrossRef]

48. Schweizer, J.; Antonini, A.; Govoni, L.; Gottardi, G.; Archetti, R.; Supino, E.; Berretta, C.; Casadei, C.; Ozzi, C. Investigating the potential and feasibility of an offshore wind farm in the Northern Adriatic Sea. Appl. Energy 2016, 177, 449-463. [CrossRef]

49. Mastrocinque, E.; Javier Ramírez, F.; Honrubia-Escribano, A.; Pham, D.T. An AHP-based multi-criteria model for sustainable supply chain development in the renewable energy sector. Expert Syst. Appl. 2020, 150, 113321. [CrossRef]

50. Saaty, T.L. Decision making with the analytic hierarchy process. Int. J. Serv. Sci. 2008, 1, 83-98. [CrossRef]

51. Saaty, R.W. The analytic hierarchy process-What it is and how it is used. Math. Model. 1987, 9, 161-176. [CrossRef] 